\title{
O USO DAS TECNOLOGIAS DIGITAIS NA FORMAÇÃO INICIAL DE PROFESSORES DE LÍNGUA PORTUGUESA: UMA PROPOSTA COM O RPG BOSS
}

\author{
Fernanda Maria Almeida dos Santos ${ }^{*}$
}

RESUMO: Este artigo apresenta uma discussão sobre o processo inicial de formação de professores de Língua Portuguesa, evidenciando de que modo interfaces digitais, como o RPG Boss, podem contribuir para a profissionalização dos licenciandos em Letras e, consequentemente, para o desenvolvimento de práticas de leitura e escrita mais dinâmicas e interativas na educação básica. O referencial teórico do trabalho concilia os estudos/análises de Gatti (2010), Gatti e Barreto (2009), Lévy (1999) e Lima e Loureiro (2016), sobre tecnologias digitais e formação docente, com as diretrizes educacionais vigentes e as discussões de Rosa (2004), Smchit (2008), Toledo (2015) e Trevisan (2004), entre outros, acerca do Roling Playing Game (RPG). Argumenta-se, a partir de uma experiência desenvolvida com discentes do curso de Letras, que propostas de formação docente que contemplem as etapas de capacitação teórico-metodológica, ação pedagógica e reflexão sobre a ação, bem como valorizem o uso de diferentes tecnologias, podem colaborar para a profissionalização dos licenciandos, seja por aproximá-los da realidade docente, através de estudos/pesquisas, planejamento, ação e análises, seja por propiciar reflexões sobre as metodologias de ensino da leitura e da escrita no contexto escolar.

PALAVRAS-CHAVE: Ensino; Formação docente; Língua Portuguesa; Tecnologias Digitais.

\section{Introdução}

A sociedade contemporânea acompanha, incita e favorece o desenvolvimento de um sistema interativo, síncrono e assíncrono, de alcance global, proveniente dos avanços tecnológicos desencadeados a partir do final do século XX. Esse modelo interacional tem provocado alterações na estrutura social, na vida e nas (rel)ações humanas, bem como nas formas de ensinar e aprender. Desse modo, as discussões sobre docência e práticas de ensino de língua portuguesa precisam contemplar as atuais mudanças e estar vinculadas às necessidades dos sujeitos pós-modernos.

Por isso, os cursos de licenciatura em Letras, em especial, não podem deixar de reconhecer as implicações das Tecnologias Digitais nos processos de aprendizagem. E, mais do que isso, as propostas de formação docente na área de Língua Portuguesa precisam 
estar relacionadas às práticas linguísticas (multimidiáticas e multissemióticas) que permeiam um século marcado pelo avanço das tecnologias informacionais.

É nessa perspectiva que o presente trabalho propõe uma discussão sobre o processo inicial de formação de professores, analisando como as interfaces digitais - mais especificamente o programa RPG Boss - podem contribuir para a formação de graduandos da área de Letras e, consequentemente, para o desenvolvimento de práticas de leitura e escrita mais diversificadas e colaborativas no contexto escolar.

Inicialmente, o artigo apresenta reflexões sobre a formação de professores nos cursos de licenciatura em Letras e demonstra a importância da utilização das tecnologias digitais nesses cursos, com base no que a legislação educacional brasileira preconiza sobre a formação de docentes para atuar na educação básica. Em seguida, o texto revela como o RPG Boss pode ser uma importante interface no processo de aprendizagem da leitura e da escrita. Por fim, descreve uma proposta de formação docente desenvolvida com licenciandos em Letras de uma universidade pública federal, localizada no interior da Bahia, evidenciando as contribuições das tecnologias digitais para a profissionalização dos licenciandos.

Espera-se, portanto, por meio deste trabalho, alcançar o objetivo de fomentar uma discussão teórica no campo dos estudos linguísticos e, ao mesmo tempo, contribuir com pesquisadores e professores que atuam na educação superior, com reflexões sobre o uso das Tecnologias Digitais no processo de formação docente.

\section{Por que utilizar as interfaces digitais na formação dos licenciandos em Letras?}

Na contemporaneidade, o desenvolvimento e o uso crescente das Tecnologias Digitais e das redes de comunicação interativa acompanham e amplificam uma profunda mutação nas relações com o saber, possibilitando novas formas de aprendizagem. Por isso, conforme Lévy (1999), qualquer reflexão sobre os mecanismos de formação e aprendizagem na cibercultura deve ser fundamentada em uma análise prévia das mudanças hodiernas nas relações humanas com o saber. 
Antes fragmentado por rígidas áreas de conhecimento e considerado imutável, linear e totalizável, o saber é, agora, entendido como algo dinâmico, em construção permanente. Corroborando essas ideias, Lévy (1999) expõe:

No lugar de uma representação em escalas lineares e paralelas, em pirâmides estruturadas em "níveis", organizadas pela noção de prérequisitos e convergindo para saberes "superiores", a partir de agora devemos preferir a imagem de espaços de conhecimentos emergentes, abertos, contínuos, em fluxo, não lineares, se reorganizando de acordo com os objetivos ou os contextos, nos quais cada um ocupa uma posição singular e evolutiva. (LÉVY, 1999, p. 158)

Contudo, nos currículos dos cursos de Licenciatura, ainda prevalece a tradição disciplinar. Além disso, o processo formativo ocorre mais de modo mais teórico do que efetivamente prático, e as atividades de ensino nem sempre estão articuladas à pesquisa e à extensão. Refletindo acerca desses aspectos, Gatti salienta:

A forte tradição disciplinar que marca entre nós a identidade docente e orienta os futuros professores em sua formação a se afinarem mais com as demandas provenientes da sua área específica de conhecimento do que com as demandas gerais da escola básica, leva não só as entidades profissionais como até as científicas a oporem resistências às soluções de caráter interdisciplinar para o currículo [...]. (GATTTI, 2010, p. 1375)

No que concerne especificamente aos cursos de Licenciatura em Letras, além de se privilegiar uma especificação do saber (ora na área Linguística, ora no campo da Literatura), nota-se que as disciplinas práticas e/ou de caráter pedagógico não conseguem inter-relacionar três elementos essenciais para a formação/profissionalização dos graduandos: teorias linguísticas, práticas de ensino e contexto socioeducacional, gerando uma pulverização na formação dos licenciados e a frágil preparação do profissional para o exercício do magistério na educação básica.

Gatti (2010) apresenta uma análise dos currículos de 32 (trinta e dois) cursos de Licenciatura em Letras de diferentes universidades localizadas nas cinco regiões brasileiras. Para tanto, observa o projeto pedagógico dos cursos, o conjunto de disciplinas ofertadas e suas ementas. Com base nas análises realizadas, a autora confirma - entre outros aspectos 
- que: i) os cursos de Licenciatura em Letras destinam a maior parte de sua carga horária $(51,4 \%)$ a disciplinas relativas aos conhecimentos disciplinares da área, com predominância da Linguística; ii) em boa parte dos ementários analisados não foi observada uma articulação entre as disciplinas de formação específica (conteúdos da área disciplinar) e a formação pedagógica (conteúdos para a docência); iii) saberes relacionados ao uso das tecnologias estão praticamente ausentes.

Lima e Loureiro ainda acrescentam outros fatores que atestam falhas significativas no processo de formação dos licenciandos: “[...] [2] as formações não enfatizam a importância da fundamentação epistemológica das ações didáticas e metodológicas; e [3] o uso das tecnologias digitais não produz novas metodologias e didáticas". (2016, p. 146)

Nesses moldes, a formação inicial - baseada em uma proposta aplicacionista do conhecimento teórico - não prepara efetivamente os graduandos para o exercício da prática docente. E mais: trata-se de uma formação desvinculada da realidade socioeducacional e da diversidade cultural presente em nossa sociedade, bem como das práticas multimodais e multiculturais que permeiam um século marcado pelo avanço das Tecnologias Digitais. Assim sendo,

No que concerne à formação de professores, uma verdadeira revolução nas estruturas institucionais formativas e nos currículos da formação é necessária. As emendas já são muitas. A fragmentação formativa é clara. É preciso integrar essa formação em instituições articuladas e voltadas a esse objetivo precípuo. A formação de professores não pode ser pensada a partir das ciências e seus diversos campos disciplinares, como adendo destas áreas, mas a partir da função social própria à escolarização - ensinar às novas gerações o conhecimento acumulado e consolidar valores e práticas coerentes com nossa vida civil. (GATTI; BARRETO, 2009, p. 257)

Uma das maneiras de promover uma formação mais dinâmica, voltada para as práticas e valores emergentes na sociedade contemporânea, e de preparar os graduandos para o exercício do magistério é por meio de práticas que integrem as atividades de ensino, pesquisa e extensão e o uso das interfaces digitais. "As tecnologias alteram todas as nossas 
ações, as condições de pensar e de representar a realidade e, especificamente, no caso particular da educação, a maneira de trabalhar em atividades ligadas a educação escolar". (KENSKI, 2003, p. 29)

Sob esse prisma, desde o final do século XX, a legislação educacional brasileira preconiza o uso das tecnologias mais contemporâneas no processo de formação docente. $\mathrm{O}$ Decreto n 3.276, de 1999, que dispõe sobre a formação em nível superior de professores para atuar na educação básica, e dá outras providências, estabelece - em seu Artigo $5^{\circ}$, parágrafo $1^{\circ}$ - que uma das competências a serem desenvolvidas pelos professores que atuarão na educação básica diz respeito ao domínio do conhecimento pedagógico, incluindo as novas linguagens e tecnologias, considerando os âmbitos do ensino e da gestão, de forma a promover a efetiva aprendizagem dos alunos (BRASIL, 1999).

No que concerne especificamente à formação de professores de Língua Portuguesa, as Diretrizes curriculares para os cursos de Letras, de 2001, ao conceberem “a Universidade não apenas como produtora e detentora do conhecimento e do saber, mas, também, como instância voltada para atender às necessidades educativas e tecnológicas da sociedade" (BRASIL, 2001, p. 29), definem que o formando: "Deve ser capaz de refletir teoricamente sobre a linguagem, de fazer uso de novas tecnologias e de compreender sua formação profissional como processo contínuo, autônomo e permanente (BRASIL, 2001, p. 30).

Também as Diretrizes Curriculares Nacionais para a Formação de Professores da Educação Básica, em nível superior, curso de licenciatura, de graduação plena, de 2002, em seu artigo $2^{\circ}$, recomendam:

A organização curricular de cada instituição observará [...] outras formas de orientação inerentes à formação para a atividade docente, entre as quais o preparo para: [...] VI - o uso de tecnologias da informação e da comunicação e de metodologias, estratégias e materiais de apoio inovadores. (BRASIL, 2002, p. 1, grifo nosso)

Em 2015, o referido documento é atualizado, em virtude da necessidade de se articular as Diretrizes Curriculares Nacionais para a Formação Inicial e Continuada, em Nível Superior, e as Diretrizes Curriculares Nacionais para a Educação Básica (2013). Mas , do 
mesmo modo que nos documentos anteriores, o Artigo $5^{\circ}$ recomenda que a formação de profissionais do magistério conduza o(a) egresso(a):

V - à elaboração de processos de formação do docente em consonância com as mudanças educacionais e sociais, acompanhando as transformações gnosiológicas e epistemológicas do conhecimento; VI - ao uso competente das Tecnologias de Informação e Comunicação (TIC) para o aprimoramento da prática pedagógica e a ampliação da formação cultural dos(das) professores(as) e estudantes; VII - à promoção de espaços para a reflexão crítica sobre as diferentes linguagens e seus processos de construção, disseminação e uso, incorporando-os ao processo pedagógico, com a intenção de possibilitar o desenvolvimento da criticidade e da criatividade. (BRASIL, 2015, p. 6)

Nesse contexto, a docência é concebida como uma ação educativa que envolve conhecimentos específicos, interdisciplinares e pedagógicos, voltados para a construção de valores éticos, linguísticos, estéticos, políticos, sociais e culturais, e em diálogo constante com as transformações da sociedade contemporânea. Portanto, ao final do curso de formação inicial, o licenciado deverá, entre outras coisas, estar apto a "V - relacionar a linguagem dos meios de comunicação à educação, nos processos didático-pedagógicos, demonstrando domínio das tecnologias de informação e comunicação para o desenvolvimento da aprendizagem" (BRASIL, 2015, p. 8).

Obviamente, a mera vinculação dos conhecimentos teóricos ao uso das Tecnologias Digitais não garante uma transformação pedagógica, mas - sem dúvida - o desenvolvimento de práticas interativas e interpretativas, que envolvam propósitos, valores culturais e recursos tecnológicos variados, englobando os múltiplos letramentos, propicia uma aprendizagem mais autônoma e colaborativa.

Nesse sentido, a utilização das Tecnologias Digitais no processo de formação dos licenciandos em Letras pode contribuir para a profissionalização dos graduandos, sobretudo, por: i) estimular a interação entre diferentes sujeitos, espaços e saberes no processo de construção do conhecimento; ii) possibilitar uma aprendizagem pautada em ações didáticas e metodológicas vinculadas ao mundo contemporâneo e às atuais necessidades dos estudantes da educação básica; iii) propiciar mudanças de atitude do futuro professor em 
direção à inovação educativa, por meio da compreensão prática de fenômenos teóricosmetodológicos. Assim, o desenvolvimento de atividades voltadas para o uso de variadas tecnologias, a exemplo dos jogos digitais, pode promover significativas alterações na formação do docente da área de Letras e, consequentemente, no ensino de língua portuguesa na educação básica. As seções seguintes comprovam essas informações.

\section{O RPG e suas potencialidades para o trabalho com leitura e escrita na educação}

\section{básica}

Na contemporaneidade, o trabalho com leitura e escrita, na perspectiva dos múltiplos letramentos, pode ser facilitado por meio da utilização de variados programas e interfaces digitais. Os jogos digitais, em especial, quando bem trabalhados, possibilitam o desenvolvimento pessoal, social e cognitivo dos sujeitos e potencializam variados conhecimentos e estratégias de leitura, estimulando a criatividade e o raciocínio lógico dos indivíduos.

Um jogo que pode contribuir bastante para o desenvolvimento de tais habilidades, bem como para trabalho com leitura e escrita no contexto digital, é o Role Playing Game (RPG), um jogo de representação de papéis, no qual os jogadores se transportam para outra realidade social, assumindo um novos papéis e vivenciando a aventura por meio de uma personagem. Como descreve Schmit, os jogos de RPG

são atividades cooperativas nas quais um grupo de jogadores, geralmente em número de quatro a dez, cria uma história de forma oral, escrita ou animada e não-linear, utilizando-se como plano de jogo a imaginação, esboços, gestos, falas, textos e imagens. Cada um dos jogadores, com exceção de um, representa uma personagem da história, com características próprias pré-definidas. Os jogadores restantes assumem o papel de narrador (ou mestre de jogo, entre outros nomes), sendo responsável por descrever o cenário, além de representar todos os coadjuvantes, antagonistas e figurantes, denominados non-player characters ou mais comumente NPC. (SCHMIT, 2008, p. 24)

De maneira geral, o jogo é composto por três elementos principais: ambientação, história e sistema de regras. A ambientação se refere ao contexto (medieval, futurístico, histórico, cômico etc) onde acontece a história e envolve a caracterização do cenário e 
figurino das personagens. No que concerne à história, é construída de modo particular por cada jogador, a partir das cenas e do sistema de regras do jogo. O roteiro da narrativa é sempre aberto. Cada jogador dirige suas ações e, por meio da fantasia/imaginação, cria diferentes personagens, mundos e realidades em integração com o mundo dos outros participantes. Mas é válido enfatizar que, embora cada jogador construa sua aventura de modo particular, todos devem respeitar as regras gerais de funcionamento do jogo.

As regras são normalmente estabelecidas pelo Mestre - um tipo especial de jogador que: i) apresenta ao grupo de jogadores o enredo da história, com seus enigmas e charadas, e evidencia as situações que demandarão escolhas e decisões por parte dos jogadores; ii) dirige a aventura; iii) coordena todas as ações realizadas pelos participantes. É, ao mesmo tempo: roteirista, juiz/árbitro, diretor, organizador (TREVISAN, 2004).

Se o RPG fosse um videogame, o mestre seria o controle, o aparelho em si. O mestre cria o mundo de aventuras onde vivem os heróis. Ele diz aos jogadores o que acontece nesse mundo, assim como o aparelho de videogame mostra na tela da TV. O mestre também controla os inimigos que enfrentam os heróis. (...) Sempre que um jogador tenta fazer algo com seu personagem, o Mestre diz se ele conseguiu ou não. O Mestre diz como ele deve realizar sua ação, como jogar os dados, que resultados precisa conseguir... (...) O Mestre também inventa aventuras. Muitas revistas trazem numerosas aventuras prontas que um mestre pode usar. Qualquer aventura pronta pode ser modificada ou alterada, mudando seus poderes, acrescentando ou removendo coisas. Essas mudanças poder ser necessárias para tornar a aventura adequada a seu grupo de jogo. (EVANGELISTA, 2009, p. 9 apud MACIEL et al., 2017, p. 18521)

Os jogadores, por sua vez, conduzem os personagens da aventura, considerando o cenário, o tema e as regras do jogo, bem como fazem escolhas e tomam decisões. "No RPG, o jogador não é um mero espectador, mas um participante ativo, que como um ator, representa um papel e, como um roteirista, escolhe caminhos e toma decisões nem sempre previstas pelo Mestre, contribuindo na recriação da aventura" (TOLEDO, 2015, p. 10). Por isso, como afirma Marcatto,

O RPG não é competitivo. A diversão não está em vencer ou derrotar os outros jogadores, mas utilizar a inteligência e a imaginação 
para, em cooperação com os demais participantes, buscar alternativas que permitam encontrar melhores respostas para as situações propostas pela aventura. É um exercício de diálogo, de decisão em grupo, de consenso. (MARCATTO, 1996, p. 35)

Sendo assim, esse jogo, além de estimular o raciocínio lógico, o senso crítico e a comunicação interpessoal, garante a autonomia do sujeito ao lhe conferir poder para a tomada de decisões, assim como possibilita o desenvolvimento de diferentes habilidades de leitura e escrita por contato com variadas semioses.

Mas, além do clássico RPG de mesa (jogado em torno de uma mesa, por meio do uso de objetos, como lápis, papel e dados), uma modalidade de RPG bastante conhecida é o Live Actions. O que diferencia essa modalidade de jogo que se popularizou nos anos 90 do RPG de mesa é o fato de que, ao invés de descrever as ações, os jogadores as interpretam fisicamente. Nesse caso, o jogo transforma-se numa espécie de teatro, com cenário, objetos e figurinos reais.

Outra importante modalidade do jogo, que se desenvolveu - sobretudo - devido ao surgimento dos computadores e desenvolvimento de outras tecnologias digitais, é o RPG digital. O que muda agora é que, nesse jogo, os participantes vivenciam a aventura por meio de uma interface digital. $\mathrm{Na}$ verdade, as tecnologias digitais permitem não apenas que o jogador corra e pule entre plataformas, vencendo obstáculos, enfrentando inimigos e superando desafios, mas também possibilitam que o usuário crie o próprio jogo (com cenário, personagens, narrativas, obstáculos e desafios), dando livre espaço à imaginação.

Uma plataforma simples, mas bastante funcional, que possibilita a criação de jogos digitais por iniciantes é o RPG Boss. Nesse game enginer, o jogador controla uma personagem e enfrenta desafios diversos, utilizando comandos baseados na linguagem Java. Embora não exija programação, um projeto de RPG requer planejamento, criação e resolução de problemas.

Figura 1 - Logomarca do jogo RPG Boss

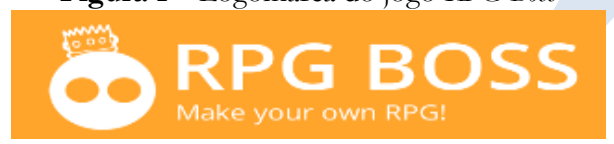

Fonte: Programa RPG Boss 
O RPG Boss pode ser utilizado em vários sistemas operacionais, como Windows, $L i$ nux e Mac. Logo na tela inicial do jogo, aparecem opções que possibilitam ao usuário criar ou editar uma narrativa.

Figura 2 - Tela inicial do jogo

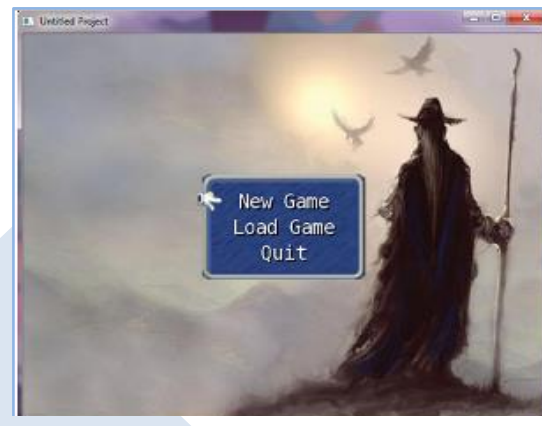

Fonte: Programa RPG Boss

Usando o mouse, o usuário poderá selecionar uma das três opções para concretizar seu objetivo.

- New Game: Usado para iniciar um novo projeto;

- Load Game: Usado para dar continuidade a um projeto iniciado anteriormente;

- Quit: Usado para sair/fechar o jogo.

Após a inicialização do projeto, o usuário se depara com uma plataforma vazia, na qual é possível montar o cenário, inserir personagens, objetos e animações, bem como incluir narrativas, utilizando os diferentes comandos da barra de ferramentas. 
Figura 3 - Tela para a construção do jogo

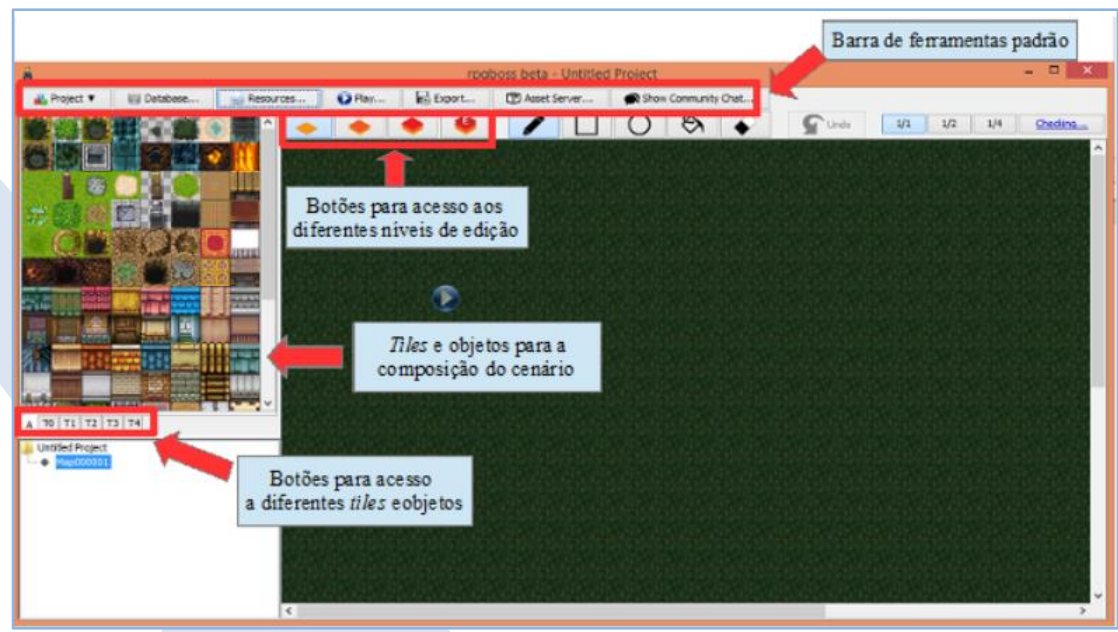

Fonte: Adaptado do Programa RPG Boss

Na primeira etapa de construção do jogo, o usuário deverá se dedicar à montagem do cenário e à inserção de objetos na plataforma. Para tanto, poderá utilizar quatro diferentes níveis de edição. No primeiro nível, é possível criar o caminho no qual os personagens irão se movimentar, usando diferentes tiles (ladrilhos), que combinados comporão chão, grama, paredes, montanhas, plantações etc. Os tiles que compõem esse nível de edição são elementos simples e não interagem com as personagens no decorrer do jogo. No entanto, alguns funcionam como obstáculos, impedindo a movimentação do protagonista no ambiente do jogo.

Já no segundo plano são introduzidos todos os objetos que irão compor o cenário. Durante o jogo, tais objetos aparecerão no mesmo nível das personagens, podendo ou não interagir com elas e criar barreiras no caminho. O terceiro plano, por sua vez, é utilizado no intuito de tornar o cenário mais real. Nele o usuário pode colocar um objeto sobre o outro, criando modulações.

Por fim, no quarto plano, além de o criador conseguir visualizar - de modo geral o cenário construído, poderá adicionar tiles que interagem, das mais variadas maneiras, com as personagens do jogo. Nesse nível de edição é possível, então, inserir bônus, animações, 
portas que se abrem com o uso de chaves e, até mesmo, transportar o protagonista para outro mapa. Em relação a esse último aspecto, é importante enfatizar que, para possibilitar a criação de uma narrativa lógica e bem estruturada, mas - ao mesmo tempo - vivenciada em diferentes lugares e caracterizada pela amplitude de acontecimentos, o jogo é organizado por meio de mapas e submapas distintos e hierarquizados.

No que concerne especificamente à inserção de personagens na narrativa, é feita por meio da janela de eventos - New Event, aberta a partir de um clique duplo sobre o local onde se deseja que ação aconteça. Posteriormente, o jogador deverá clicar no espaço em branco, nomeado de $\langle$ Sprite $\rangle$, e, então, aparecerá outra janela com diferentes personagens e objetos, posicionados de maneiras diversificadas. Após a confirmação da escolha da personagem, ela aparecerá automaticamente no cenário do jogo.

Figura 4 - Janelas para a inserção de personagens no RPG Boss

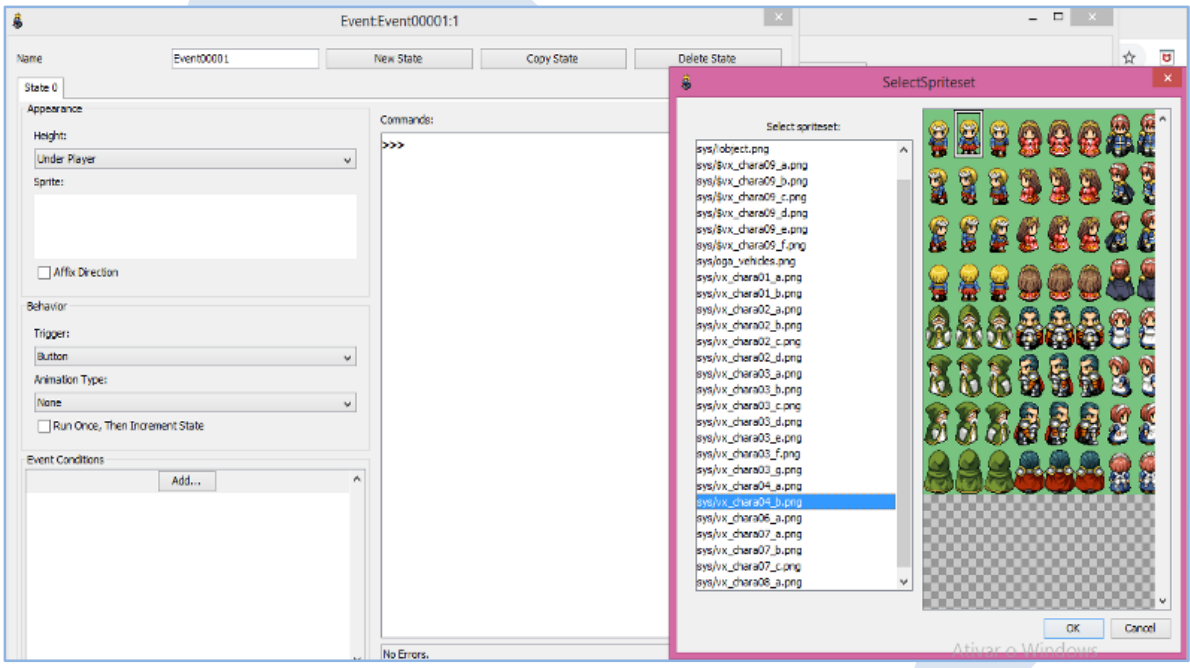

Fonte: Programa RPG Boss

Por meio do editor de eventos, também é possível teletransportar a personagem para outro espaço, adicionar textos, mensagens, diálogos e perguntas/respostas, bem como inserir efeitos e animações no jogo. Nota-se, desse modo, que 
[...] o software possui uma diversidade de recursos que permitem a construção de um jogo eletrônico no estilo de RPG, ou seja, possui todas as características de uma partida convencional, porém o papel do mestre da partida é desempenhado em dois momentos: o primeiro é quando o designer cria a aventura como um todo e o segundo é executado pelo próprio jogo já constituído, no momento em que a partida é iniciada [...]. (ROSA, 2004, p. 42)

Portanto, o uso do programa no contexto escolar - seja para a preparação de designers, seja para a experimentação das narrativas - pode propiciar aos alunos distintas aprendizagens e interações no ambiente virtual, além de incitar a imaginação, a criatividade e o raciocínio lógico e potencializar diferentes habilidades de leitura e escrita. Como o jogo valoriza distintas formas de representação do conhecimento e diferentes potenciais para a criação de significado, é também um excelente recurso para o trabalho com os letramentos em sala de aula. Mas, para isso, o docente precisa estar devidamente preparado para o trabalho com os diferentes modos de uso da linguagem e perceba a língua e os outros modos de constituição do sentido como elementos dinâmicos, os quais são constantemente reconstruídos pelos sujeitos à medida que esses se empenham para alcançar os mais variados propósitos culturais.

Portanto, segundo Bittencourt e Giraffa (2003), a utilização do RPG requer, como toda e qualquer atividade educacional, um planejamento e organização, nunca deve ser utilizado de maneira descontextualizada. Ademais, requer uma articulação entre diferentes conhecimentos linguísticos e tecnológicos. E é nessa perspectiva que a seção a seguir apresentará uma experiência de formação docente para o trabalho com o programa RPG Boss.

\section{Relatos de uma experiência de formação docente}

No intuito de aliar o ensino de língua portuguesa ao uso das tecnologias digitais na educação básica e, ao mesmo tempo, contribuir para a formação dos licenciandos em Letras numa universidade pública localizada no interior da Bahia - a Universidade Federal do Recôncavo da Bahia (UFRB/ Campus de Amargosa), por meio de atividades que envolvem ensino, pesquiso e extensão, elaboramos uma oficina pedagógica para o trabalho com o RPG Boss. É importante salientar que a oficina integrou as atividades desenvolvidas no 
âmbito do Projeto de Pesquisa As Interfaces Digitais e o Ensino de Lingua Portuguesa na Educação Básica, nos anos de 2017 e 2018.

O referido projeto foi esboçado, inicialmente, com o objetivo geral de investigar o processo de ensino e aprendizagem da escrita da Língua Portuguesa em contextos tecnológicos, analisando os entraves, desafios e contribuições das interfaces digitais para o aprendizado de estudantes do ensino fundamental: anos finais. No entanto, a investigação logo evidenciou que um dos principais entraves para o ensino de língua atrelado ao uso das tecnologias mais contemporâneas no contexto educacional diz respeito às lacunas no processo de formação inicial dos licenciandos em Letras. Por isso, foi necessário ampliar os objetivos do projeto e promover atividades de formação para o trabalho com os multiletramentos, atentando-se para alguns objetivos que embasam o uso das tecnologias mais contemporâneas nos cursos de formação de professores:

Dar a conhecer as novas tecnologias da informação e comunicação (o que são e como funcionam); analisar sua articulação com os processos de ensino-aprendizagem (vantagens e desvantagens da aplicação da tecnologia no currículo); permitir que o futuro professor adquira habilidades mínimas no manejo de hardware e software; permitir uma mudança de atitudes do futuro professor em direção à inovação educativa, numa mudança de atitude através do conhecimento. (MARINHO, 2008, p. 27)

Primeiramente, o processo formativo referente ao tema envolveu 08 (oito) graduandos do curso de Letras (matriculados do $6^{\circ}$ ao $10^{\circ}$ semestre) que integravam o projeto de pesquisa anteriormente mencionado, sendo 01 (um) estudante de gênero masculino e 07 (sete) de gênero feminino. De maneira geral, o trabalho desenvolvido com esses estudantes englobou as seguintes etapas: i) capacitação teórico-metodológica; ii) ação pedagógica; iii) reflexão sobre a ação.

No que concerne à primeira etapa - capacitação teórico-metodológica, foi fundamental para subsidiar, epistemologicamente, as práticas didático-pedagógicas e desenvolver o envolvimento natural dos sujeitos com os elementos e interfaces necessárias à ação pedagógica. Nessa fase, os licenciandos foram motivados para o trabalho com o RPG Boss e orientados quanto uso das ferramentas do jogo. Para tanto, contou-se com a colaboração 
de um docente da área de Educação Matemática e especialista em jogos eletrônicos, o professor Dr. Jaylson Teixeira (UFRB). Ademais, privilegiou-se o desenvolvimento de ações, como: realização de pesquisas; leitura de textos teóricos sobre o tema, em ambiente virtual e não virtual; construção de jogos digitais; análise interativa dos jogos produzidos. É importante ressaltar que, para a produção dos jogos, os discentes foram subdividos em grupos e incentivados a elaborar narrativas, com base diferentes gêneros textuais: conto, crônica, poema, fábula e outros.

Já por meio da segunda etapa - a ação pedagógica, objetivou-se ampliar a aprendizagem dos discentes no que diz respeito à preparação de atividades e ao desenvolvimento de ações pedagógicas. Essa etapa foi segmentada em duas fases: i) planejamento de atividades; ii) realização de oficinas pedagógicas. Evidentemente, essas ações contaram com a parceria de escolas da rede pública, bem como apoiaram-se na análise do contexto educacional - realizada a partir de dados obtidos por meio de questionários anteriormente aplicados com estudantes e professores de uma escola de ensino fundamental (anos finais). Ademais, privilegiou-se um dos jogos construídos pelos licenciandos na etapa anterior do processo formativo, com base na crônica "A bola”, de Luís Fernando Veríssimo. 
Figura 5 - Trechos do jogo construído com base na crônica "A bola"
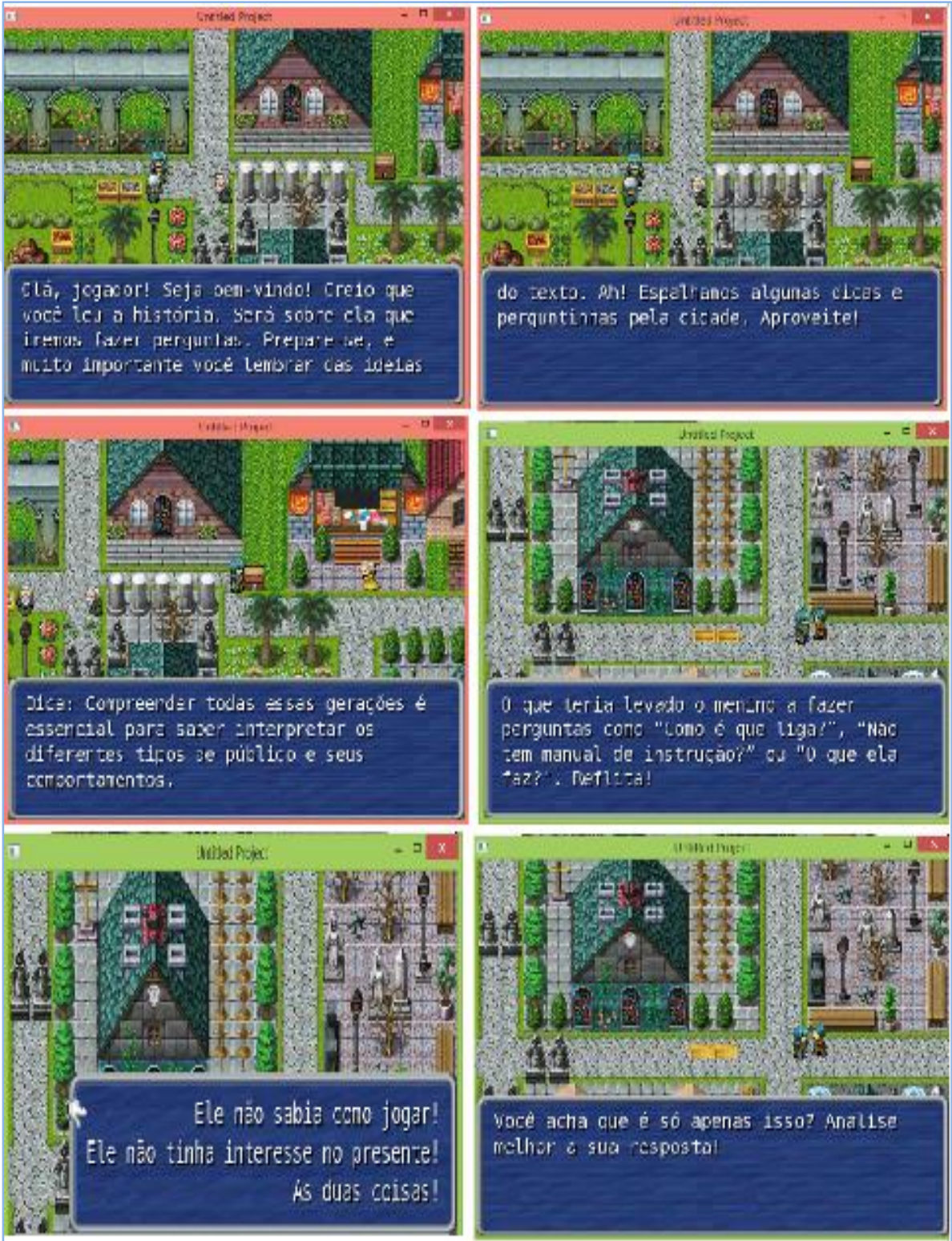

Fonte: Autoria própria 
Figura 6 - Trechos do jogo que representam a mudança de fase

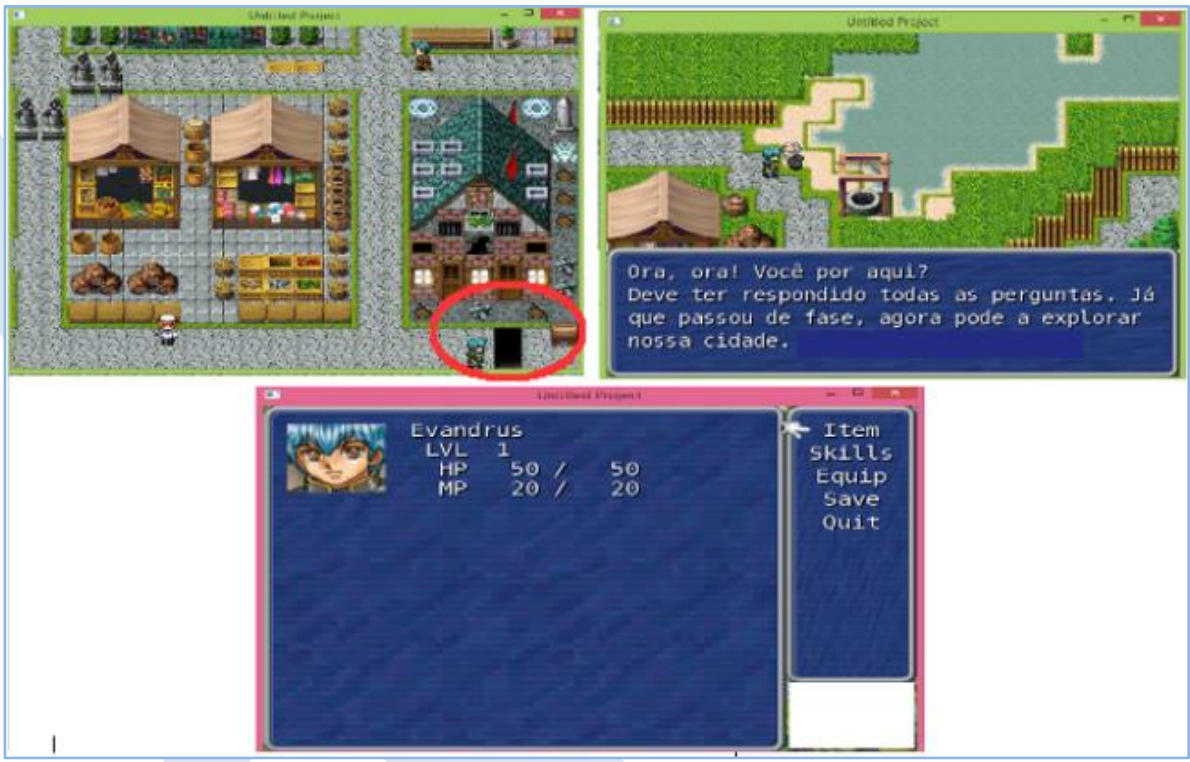

Fonte: Autoria própria

O jogo elaborado, como evidencia a Figura 5, possibilita aos jogadores se inserir no mundo da leitura e da escrita por meio da fantasia e da imaginação. No decorrer da aventura, construída de modo não linear por cada jogador, o protagonista encontra instruções acerca do jogo, mensagens e baús contendo dicas sobre o texto. O herói também precisa dialogar com outras personagens, desvendar enigmas e charadas, bem como enfrentar diferentes desafios (responder a perguntas feitas pelas personagens que aparecem na narrativa). Além disso, as questões inseridas no jogo sempre geram outros diálogos e possibilitam que o personagem/jogador reflita acerca da sua resposta.

O jogo construído também permite aos sujeitos mudar de fase por meio de portas que teletransportam os jogadores para outro espaço de narrativa, quando eles obtêm a pontuação necessária para isso, como demonstra a Figura 6. 
Nota-se, desse modo, que - além de promover a diversão e a interatividade - o jogo elaborado pelos licenciandos possibilita aos estudantes da educação básica não apenas refletir sobre o texto "A bola" por meio de diferentes perguntas e respostas, mas oportuniza - sobretudo - distintas possibilidades de leitura. Através da associação entre as diferentes semioses e as interações desenvolvidas nos ambiente virtual por meio do jogo, é possível compreender os variados modos de representação do significado, seja por meio da análise do cenário e do caminho a ser percorrido pelo protagonista, seja pelas decisões a serem tomadas pelo jogador à medida que os desafios aparecem na aventura. Ademais, as variadas situações experienciadas pela personagem principal instigam a criatividade e a autonomia dos sujeitos, ajudando-lhes a lidar com um mundo cada vez mais digital.

Considerando-se, então, as potencialidades do jogo, foi elaborada uma sequência de atividades para o trabalho com discentes do $6^{\circ}$ e $7^{\circ}$ anos do ensino fundamental de uma escola da rede pública estadual situada no interior da Bahia. O Quadro 1 expõe o conjunto de atividades planejadas pelo grupo de licenciandos em processo formativo.

Quadro 1 - Oficina elaborada para o trabalho com estudantes do $6^{\circ}$ e $7^{\circ}$ ano do ensino fundamental

\begin{tabular}{|c|l|l|}
\hline \multirow{5}{*}{ JOGO } & $\begin{array}{c}\text { SEQUÊNCIA } \\
\text { METODOLÓGICA }\end{array}$ & \multicolumn{1}{c|}{ ATIVIDADES } \\
\hline \multirow{5}{*}{ RPG Boss } & $\begin{array}{l}\text { Apresentando } \\
\text { o jogo }\end{array}$ & $\begin{array}{l}\text { - Leitura do texto “A bola", disponível em mídia digital; } \\
\text { - Prática do jogo de RPG, a partir da leitura do texto; Obs.: O jogo } \\
\text { envolveu conhecimentos interdisciplinares sobre o gênero/ tema. }\end{array}$ \\
\cline { 2 - 4 } & $\begin{array}{l}\text { Conhecendo } \\
\text { o jogo }\end{array}$ & $\begin{array}{l}\text { - Observação/análise de elementos constitutivos do jogo, bem } \\
\text { como de elementos multissemióticos presentes na narrativa. }\end{array}$ \\
\cline { 2 - 4 } & $\begin{array}{l}\text { Sistematizando } \\
\text { o conhecimento }\end{array}$ & $\begin{array}{l}\text { - Criação de uma História em Quadrinhos no site www.pix- } \\
\text { ton.com/br, a partir de elementos da narrativa. } \\
\text { Obs.: Por conta do tempo destinado à oficina, os estudantes não } \\
\text { desenvolveram habilidades relativas à produção do jogo. }\end{array}$ \\
\cline { 2 - 4 } & $\begin{array}{l}\text { Compartilhando } \\
\text { o conhecimento }\end{array}$ & $\begin{array}{l}\text { - Visualização das histórias construídas pelos colegas; } \\
\text { - Interação virtual entre os alunos. }\end{array}$ \\
\cline { 2 - 3 } & $\begin{array}{l}\text { Avaliando } \\
\text { o processo de } \\
\text { aprendizagem }\end{array}$ & $\begin{array}{l}\text { - Para a avaliação das atividades realizadas na oficina, os alunos fo- } \\
\text { ram orientados a postar mensagens num grupo fechado criado na } \\
\text { rede social Facebook (no intuito de continuarmos virtualmente inte- } \\
\text { ragindo com eles após as oficinas). }\end{array}$ \\
\hline
\end{tabular}

Fonte: Elaboração própria

As oficinas ocorreram nos dias 18 e 19 de julho de 2018, no laboratório de informática da Universidade (já que não havia na escola suporte tecnológico necessário para o desenvolvimento das atividades), e contemplaram quatro diferentes grupos de estudantes, 
subdivididos por dia e turno de atividade. Cada oficina teve duração total de 3 (três) horas e foi realizada em turno oposto ao período de aulas dos discentes.

Figura 7 - Fotos registradas durante a oficina
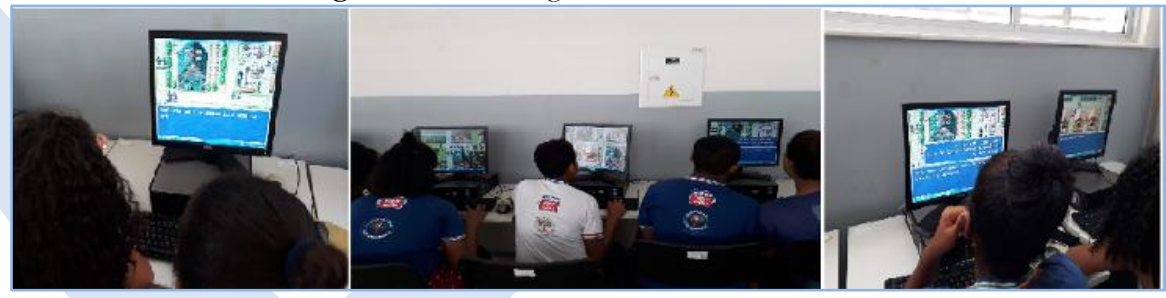

Fonte: Arquivo digital do pesquisador

Apesar do curto tempo destinado para a realização das oficinas, percebeu-se que os objetivos da atividade foram cumpridos e que os alunos puderam desenvolver, de maneira criativa e dinâmica, diferentes estratégias de leitura e escrita por meio do jogo e ativar os seguintes conhecimentos: conhecimento linguístico, conhecimento de mundo, conhecimento referente a modelos globais de textos e conhecimento sociointeracional. (cf. ANTUNES, 2010)

Para se chegar a tais conclusões, foi de fundamental importância a terceira etapa do processo formativo dos licenciandos - a reflexão sobre a ação. Em relação a esse último aspecto, é válido ressaltar que duas integrantes do projeto Nessa etapa, os graduandos foram estimulados a analisar as ações desenvolvidas (contribuições, dificuldades enfrentadas e desafios); observar as atividades produzidas pelos alunos; produzir relatos de experiência e/ou artigos científicos com base nos resultados encontrados; apresentar as experiências de ensino e os trabalhos produzidos por meio delas, em seminários e eventos acadêmicos. Em relação a esse aspecto, é válido ressaltar que uma integrante do projeto se envolveu tanto no trabalho com RPG que elegeu esse tema para a produção do Trabalho de Conclusão do Curso.

Fica evidente, então, que as diferentes etapas de formação docente propiciaram aos licenciandos diferentes conhecimentos e habilidades, tanto no que concerne ao uso das interfaces digitais, quanto no que diz respeito ao planejamento/elaboração/desenvolvimento 
de atividades pedagógicas no âmbito da leitura e escrita. De modo teórico e prático, os discentes puderam se aproximar da realidade docente, a qual engloba - continuamente estudos/pesquisas, planejamento, ação e análises, bem como refletir sobre as metodologias de ensino e os desafios que precisam ser enfrentados para que se possa utilizar diferentes tecnologias no contexto escolar.

Portanto, é possível afirmar que as ações desenvolvidas contribuíram, de um lado, para a profissionalização de estudantes do curso de Licenciatura em Letras da UFRB e, de outro, para o desenvolvimento de práticas pedagógicas inovadoras na educação básica. Em consonância com Rojo (2009), acreditamos que, para ser ética e democrática, a escola precisa estar atenta às múltiplas exigências do mundo contemporâneo e desenvolver atividades que visem, sobretudo, envolver os educandos em diferentes práticas de uso social da leitura e da escrita, aprimorando as competências e habilidades linguísticas desses sujeitos. Mas, sem dúvida, o caminho inicial é sempre processo de formação de professores, seja daqueles que irão atuar na educação básica, seja dos que já estão em efetivo exercício docente.

\section{Conclusão}

O presente trabalho apresentou uma experiência de formação docente desenvolvida com graduandos do Curso de Letras da Universidade Federal do Recôncavo da Bahia, no âmbito do projeto As Interfaces Digitais e o Ensino de Lingua Portuguesa na Educação Básica. Por meio do trabalho com as tecnologias digitais, mais especificamente com o programa $R P G$ Boss, objetivou-se contribuir com a profissionalização dos licenciandos e, consequentemente, com o processo de ensino e aprendizagem de língua portuguesa na educação básica.

A discussão teórica apresentada inicialmente visa salientar a importância do uso das interfaces digitais nos atuais processos de formação de professores e evidenciar as potencialidades do jogo para o desenvolvimento pessoal, social e cognitivo dos sujeitos, bem como para o aprendizado da leitura e da escrita a partir de textos interativos e multissemióticos. Evidentemente, tal discussão está alinhada com a experiência de formação docente desenvolvida com base no RPG Boss, por meio de três etapas inter-relacionadas: capacitação teórico-metodológica, ação pedagógica e reflexão sobre a ação. 
De maneira geral, as reflexões e propostas apresentadas neste artigo reiteram, no mínimo, três aspectos relevantes e interligados sobre o processo de formação inicial dos professores de Língua Portuguesa: i) para ser mais profícua, a formação docente deve ser pautada em atividades que articulem teorias linguísticas, práticas de ensino e contexto socioeducacional; ii) na contemporaneidade, deve-se valorizar uma formação voltada para o desenvolvimento de práticas de leitura e escrita diversificadas, colaborativas e multimodais, sendo crucial - portanto - a utilização das tecnologias digitais, de modo dinâmico e interativo; iii) os jogos digitais são uma importante ferramenta para o trabalho com os letramentos na educação básica, seja por estimular a fantasia e imaginação e possibilitar a autonomia dos indivíduos, seja por promover múltiplas aprendizagens e propiciar a interação entre diferentes sujeitos, espaços e saberes, no processo de construção do conhecimento.

Portanto, espera-se que este trabalho possa auxiliar pesquisadores e professores que atuam na educação superior, com reflexões acerca do uso das tecnologias e jogos digitais no processo de formação dos licenciados em Letras.

\title{
THE USE OF DIGITAL TECHNOLOGIES IN THE INITIAL TRAINING OF PORTUGUESE LANGUAGE TEACHERS: A PROPOSAL WITH RPG BOSS
}

\begin{abstract}
This article presents a discussion on the initial process of training Portuguese language teachers, showing how digital interfaces, such as the RPG Boss, can contribute to the professionalization of undergraduate students in Letters and, consequently, to the development of reading and writing practices. dynamic and interactive writing in basic education. The theoretical framework of the work reconciles the studies/analyzes of Gatti (2010), Gatti and Barreto (2009), Lévy (1999) and Lima and Loureiro (2016), on digital technologies and teacher training, with the current educational guidelines and the discussions of Rosa (2004), Smchit (2008), Toledo (2015) and Trevisan (2004), among others, about the Roling Playing Game - RPG. It is argued, based on an experience developed with students of the Letters course, that teacher training proposals that include the stages of theoretical-methodological training, pedagogical action and reflection on the action, as well as value the use of different technologies, can collaborate for the professionalization of undergraduate students, either by bringing them closer to the teaching reality, through studies/ research, planning, action and analysis, or by providing reflections on the teaching methodologies of reading and writing in the school context.
\end{abstract}

KEYWORDS: Digital Technologies; Portuguese language; Teacher training; Teaching. 


\section{REFERÊNCIAS}

ANTUNES, I. Análise de textos: fundamentos e práticas. SP: Parábola Editorial, 2010. (Estratégias de ensino; 21).

BITTENCOURT, João Ricardo; GIRAFFA, Lucia Maria. Modelando Ambientes de Aprendizagem Virtuais utilizando Role-Playing Games. In: XIV SIMPÓSIO BRASILEIRO DE INFORMÁTICA NA EDUCAÇÃO, 14, 2003. Rio de Janeiro. Anais do XIV Simpósio... Rio de Janeiro: SBC, 2003.

BRASIL. Decreto $n^{\circ} 3.276$, de 06 de dezembro de 1999. Dispõe sobre a formação em nível superior de professores para atuar na educação básica, e dá outras providências, 1999. Disponível em: https://presrepublica.jusbrasil.com.br/legislacao/110851/decreto-327699. Acesso em: 22 abr. 2020.

BRASIL. Ministério da Educação. Diretrizes Curriculares Nacionais Gerais da Educação Básica. Brasília, DF, MEC/SEB, 2013. Disponível em: http://portal.mec.gov.br/docman/julho2013-pdf/13677-diretrizes-educacao-basica-2013-pdf/file. Acesso em: 22 abr. 2020.

BRASIL. Parecer CNE/CP $n^{0}$ 9, de 8 de maio de 2001. Diretrizes curriculares nacionais para a formação de professores da educação básica, em nível superior, curso de licenciatura, de graduação plena. Disponível em: http:// portal.mec.gov.br/cne/arquivos/pdf/009.pdf. Acesso em: 22 abr. 2020.

BRASIL. Resolução CNE/CP $n^{0} 1$, de 18 de fevereiro de 2002. Institui Diretrizes Curriculares Nacionais para a Formação de Professores da Educação Básica, em nível Superior, Curso de Licenciatura, de graduação Plena, 2002. Disponível em: http:/ / portal.mec.gov.br/pnaes/323-secretarias-112877938/orgaos-vinculados-82187207/12861formacao-superior-para-a-docencia-na-educacao-basica. Acesso em: 22 abr. 2020.

BRASIL. Resolução CNE/CP n. 02/2015, de $1^{\circ}$ de julho de 2015. Define as Diretrizes Curriculares Nacionais para a formação inicial em nível superior (cursos de licenciatura, cursos de formação pedagógica para graduados e cursos de segunda licenciatura) e para a formação continuada, 2015. Disponível em: http://portal.mec.gov.br/pnaes/323-secretarias-112877938/orgaos-vinculados-82187207/12861-formacao-superior-para-a-docenciana-educacao-basica. Acesso em: 22 abr. 2020.

GATTI, B. A. Formação de Professores no Brasil: características e problemas. Educação \&. Sociedade, Campinas, v. 31, n. 113, p. 1355-1379, out.-dez, 2010.

; BARRETTO, E. S. S. (Orgs.). Professores do Brasil: impasses e desafios. Brasília: UNESCO, 2009.

KENSKI, V. M. Tecnologias e ensino presencial e a distância. Campinas-SP: Papirus, 2003. (Série Prática Pedagógica).

LÉVY, P. Cibercultura. Tradução de Carlos Irineu da Costa. Rio de Janeiro: Editora 34, 1999. (Coleção TRANS). 
LIMA, L.; LOUREIRO, R. C. Relação entre Tecnologias Digitais e Docência: a Compreensão de Licenciandos sobre Tecnodocência. Informática na Educação: Teoria \& Prática. Porto Alegre, v.19, n.3, p. 145-160, set./dez. 2016.

MACIEL, J. A. et al. Oficina RPG: uma aventura histórica, como metodologia no desenvolvimento do processo de ensino-aprendizagem do fundamental II. In: XIII CONGRESSO NACIONAL DE EDUCAÇÃO EDUCERE, 13, 2017, Curitiba. Anais do XIII Congresso... Curitiba: Editora Universitária Champagnat, 2017. p. 18518-18528.

MARCATTO, A. Saindo do Quadro: Uma Metodologia Educacional Lúdica e Participativa baseada no Role Playing Game. São Paulo: Exata Comunicação e Serviços S/C LTDA, 1996.

MARINHO, S. P. P. As tecnologias digitais no currículo da formação inicial de professores da educação básica: o que pensam alunos de licenciatura. Relatório técnico de pesquisa. Belo Horizonte: PUC-Minas, 2008.

ROJO, R. Letramentos múltiplos, escola e inclusão social. São Paulo: Parábola Editorial, 2009.

ROSA, M. Role Playing Game Eletrônico: uma tecnologia lúdica para aprender e ensinar Matemática. 170f. Dissertação (Mestrado em Educação Matemática) - Instituto de Geociências e Ciências Exatas, Universidade Estadual Paulista, Rio Claro-SP, 2004.

SCHMIT, W. L. RPG e Educação: alguns apontamentos teóricos. 284 f. Dissertação (Mestrado em Educação) - Centro de Educação, Comunicação e Artes., Universidade Estadual de Londrina, Londrina, 2008.

TOLEDO, E. A. O RPG como estratégia de ensino: uma proposta para o ensino de profissões. Guarapuava-PR: PDE, 2015.

TREVISAN, J. M. Dicas de Mestre II: Dragão Brasil Especial. São Paulo: Talismã, 2004.

Recebido em: 01/05/2020.

Aprovado em: 03/06/2020. 